\title{
A COMPARISON REVIEW OF AUTOMATED CONSTRUCTION SCHEDULING METHODS
}

\author{
Maryam Montazer ${ }^{1}$, Danijel Rebolj ${ }^{2}$ and Detlef Heck ${ }^{3}$
}

\begin{abstract}
Scheduling is considered the major part of the planning phase in construction project life cycle. Traditional manual scheduling methods, especially in large-scale projects with huge amount of activities and various construction methods and resource types still remain as the time-consuming, error-prone and complex process. Therefore, diverse construction framework and templates have been developed to automatically generate the construction schedules, not only to increase the accuracy and speed of scheduling but also to decrease the substantial manual efforts in construction project planning, significantly. This article reviews the research on automated construction scheduling and classifies them into three main categories including the Artificial intelligence (AI)-based scheduling, simulation-based scheduling and integrated BIM-based scheduling. The strengths and weaknesses of some specific methods are identified and discussed. Finally, advantages of Integrated BIM-based scheduling in comparison with other methods have been demonstrated, and a new direction for further research indicated.
\end{abstract}

Keywords: Automated construction scheduling, simulation based scheduling, knowledge-based scheduling, Integrated BIM-based scheduling.

\section{INTRODUCTION}

Construction schedule development process as the main part of time management phase in construction project management consists of activity definition, activity sequencing, activity duration estimation, schedule development and schedule control. The project schedule as the output of schedule development process, defines the start date and expected finish date of each activity (PMI 2008). Despite of the existence of many scheduling software, the expertise and practical experience of schedulers have still a significant role in decision-making process and project scheduling. On the other hand, one of the main responsibility of a scheduler in a construction project is to establish a proper coordination between resources (e.g. labour, materials and equipment) to give a physical form to the construction plans within predefined time and considered budget. In fact, due to the huge amount of activities in the large-scale projects, manual scheduling and resource assignment remained a time-consuming and error-prone process during construction planning. Therefore, based on mentioned limitations and requirements, the research interest in the field of automated generation of construction schedules has emerged and improved rapidly. Generation of construction schedules consists of identification the required construction activities, determination of activity

$1 \quad$ PhD Candidate, Faculty of Civil Engineering Sciences, Institute of Construction management and Economy, Graz University of Technology, Graz, Austria, maryam.montazer@student.tugraz.at

2 Professor, Faculty of Civil Engineering, Transportation Engineering and Architecture, University of Maribor, Maribor, Slovenia, Danijel.rebolj@um.si

3 Professor, Faculty of Civil Engineering Sciences, Institute of Construction management and Economy, Graz University of Technology, Graz, Austria, detlef.heck@tugraz.at 
relationships and computation of activity and project duration considering different construction methods and resource requirements. Research and development in automatic generation of construction schedules has begun in the mid-70s. In this study, some of the most highlighted methods in this field have been reviewed and classified in to three main categories including AI-based scheduling (Hendrickson et al. 1988), Simulation-based scheduling and Integrated BIM-based scheduling (Liu et al. 2015). In addition, evaluation among the reviewed methods has been implemented and the results compared in terms of utility, level of scheduling as well as capability of optimized schedules production and level of automation.

\section{CATEGORIES OF AUTOMATED SCHEDULING METHODS}

\subsection{Artificial intelligence (AI)-based scheduling}

Artificial intelligence theory can be considered as an approach, which enables a computer systems to perform tasks, which normally require the human intelligence such as human reasoning process (Rolston 1988). The knowledge-based, expert systems method and Case-based reasoning (CBR) can be considered applications of AI technology in automated construction planning. The required and relevant knowledge is represented in form of production rules, frame and logics. The AI-based scheduling systems iterate the human decision-making and act as an expert scheduler. There have been many research efforts in generating construction plans using AI-based systems, whereby, GHOST (Navinchandra et al. 1988), OARPLAN (Darwiche et al. 1989) and OPLAN (Currie and Tate 1991) can be seen as the most highlighted examples.

\subsubsection{Knowledge-based scheduling}

Knowledge-based scheduling operates based on integration of a product model with the AI solutions. Ayman et al., (1991) integrated 3D-CAD models and AI into the automated knowledge-based planning system KNOW PLAN to overcome the inevitable limitations of network-based methods and to visually simulate the construction process. The required sequencing rules between activities have been reasoned using extracted geometry and knowledge rules stored in a 3D-CAD model and a knowledge-based system, respectively. Object Oriented Programming (OOP) methodology has been used for the required data organisation, e.g. grouping relevant attributes into building objects. Cherneff et al. (1991) proposed a prototype system to automate construction scheduling through integration of CAD, knowledge based programming and data base techniques. The 2D prototype called Builder included Draw knowledge module (KM), which produced semantic network representation (SNR) from CAD model and Planner KM, which creates project networks and schedules. Bjork (1994) proposed a basic instance of object hierarchy model which categorized the building objects according to their functionality. Afterwards, Fischer and Aalami (1996) interpreted and linked the 3D CAD model to the product model of Bjork (1994). They defined five distinct attributes in symbolic activity-based construction method models including domain, constituting activities, activity sequencing, constituting objects and resource requirements to consider the effects of applied construction method on required resources, costs estimation and project duration. Furthermore, component constraints and activity constraints have been applied for sequencing the activities. Finally through interaction of construction method and product model, at desired level of details (LoD), the hierarchical process model of project has been generated. Kataoka (2008) proposed an automated planning system in 
which the predefined and editable construction method templates that were stored in the knowledge base, have been combined with the simple geometry data of 3D building model elements to generate different construction plans through proposed Structural Planning interpretable templates (SPLIT) system.

\subsubsection{Expert systems}

Expert systems simulate the reasoning of an expert by utilization the domain specific knowledge. The Knowledge base, inference engine, short term memory, explanation module and knowledge acquisition module are the most common components of Expert systems (McGartland and Hendrickson 1986). Hendrickson et al. (1988) proposed construction PLANEX to generate the construction schedules based on expert system. Wang (2001) has developed an expert system ESSCAD through integration of construction scheduling and CAD drawing. This system automatically obtained and interpreted the required architectural data from $\mathrm{CAD}$ model and then generated the primary construction schedules only for reinforced concrete frame structure building via knowledge-based systems programming and software integrating techniques. ESSCAD should be improved by enhancing its drawing interpreting functions and expanding the knowledge bases and data bases to capture all types of buildings.

\subsubsection{Case-Based Reasoning (CBR)}

In the CBR method a new problem is solved by retrieving similar experienced case(s), reusing the knowledge of the case(s), revising the solution using previous case(s) and retaining the new experience by merging it into the existing case-base (Aamodt and Plaza 1994). Tauscher et al. (2007) investigated the application of CBR for generating construction schedules which included different execution alternatives using tasks with associated constraints. They applied Feature Logic theory to describe tasks and their constraints, which led to generate the schedules at any time in the process, automatically. The associated tasks, relevant constraints and execution objectives, have been stored as solutions in case base to support planners during definition of new solutions for the current project. Xu and Muñoz-Avila (2008) proposed CaBMA prototype as a case-based planning assistant and added a knowledge layer to the project management software. They automatically mapped the WBSs and task dependencies from previous projects to hierarchical task network (HTN) representations and stored them as cases in case-base. In HTN planning, the complex tasks could be decomposed into sub tasks iteratively (Erol et al. 1994). The stored cases have been captured, generalised, refined and reused to generate WBSs for new planning projects via CBR approach.

\subsection{Simulation-based scheduling}

Among the classical simulation types e.g. discrete event, continuous, and Monte Carlo simulations, utilization of discrete event simulation (DES) well suited for construction scheduling due to its ability in defining the total project duration and taking the resources into consideration, simultaneously. Development of STROBOSCOPE (State and Resource-based simulation of construction process) (Martínez 1996) and SIMPHONY (Mohamed 2000) simplified the process of data input preparation and data output interpretation in the simulation models, significantly. Zhang et al. (2002) incorporated DES simulation with popular critical path method (CPM) networks to develop an activity-based simulation scheduling model. Akbas (2004) reported a process modelling and simulation approach for the automated scheduling of the construction projects in which geometry was added as an integral part to the process model. Lu (2003) 
proposed a simplified discrete-event simulation approach (SDESA), in which the incorporation of the constructive attributes from existing event/activity based methods into a simplified approach has been done. Lu et al. (2008) through incorporation of SDSEA and particle swarm optimization (PSO) developed an automated solution for resource-constrained CPM so-called S3, in order to decrease the total project duration and optimize procurement of resources. Wu et al. (2010) introduced a new methodology to automate the generation of schedules in appropriate LoD with pattern-based construction methods and constraint-based DES simulation. In order to automating the data input creation for simulation, a 3D-model based application has been developed to make the hierarchical process and product model.

\subsection{Integrated BIM-based scheduling}

BIM-based scheduling systems are categorized as Passive BIM and Active BIM systems which consider the 4D visualization features and the decision-making functions, respectively (Moon et al. 2013). Tauscher et al. (2009) introduced a novel approach in automatic generation of construction schedules by using BIM models and retrieving the stored former cases through CBR approach. The stored cases included the execution problem and scheduling solution parts in which the requirements and a single task/elementary schedule have been described, respectively. In the meanwhile, König et al. (2012) proposed an intelligent BIM-based scheduling using DES. The input data for constraint-based simulation have been provided by linked BIM data and two general reusable template types in order to comfort the definition of realistic simulation models, considerably. Afterwards, Wang et al. (2014) developed an interface system to integrate BIM quantity take-off (QTO) information and an operation simulation in order to generate the project-level schedules. The main core of this system was Duration estimation interface (DEI) module, which integrated BIM model, MS Access database, Stroboscope simulation language and MS project. Triple task durations and project schedules have been produced as the output of simulation through numerous iterations. Kim et al. (2013) developed a framework in order to enhance the interoperability between BIM authoring model and scheduling software. The implementation of this mentioned system consisted in utilization the embedded information in BIM model through ifcXML and generation of construction schedule through productivity rate and user-defined sequencing rules. Liu et al. (2015) developed a prototype system for automated generation of optimized schedules under resource-constrained for panelised construction in which an in-depth integration has been done between BIM model in Revit, construction process simulation in SIMPHONY, and PSO. Moreover, significant product information including connections, supports, topology and functionalities have been used in this proposed prototype. Wang and Song (2015) developed an automatic scheduling scheme through integration of IFC rules and adaptive Genetic algorithm (GA). The key significance of the proposed method was creation of a constraint relation matrix including building model components and their location based on combination of BIM files produced by REVIT and relevant rules stored in ontology knowledge base.

\section{METHOD COMPARISON}

In order to highlight the strength and weaknesses of automated scheduling methods in above-mentioned categories, five specific methods have been chosen and assigned to the letters A-E. Letters A and B refer to the results of (Fischer and Aalami 1996) and (Wang 2001) under the category of AI-based scheduling and letters $C$ to E refer to the results of 
(Tauscher et al. 2009), (Wang et al. 2014) and (Liu et al. 2015) under the category of Integrated BIM-based scheduling. Letters A and B belong to knowledge-based scheduling and expert systems, respectively. Letter $\mathrm{C}$ refers to the integration of BIM with CBR. Letters D and E pertain to the integration of BIM with simulation-based methods. The comparison in term of utility, level of scheduling together with the capability of optimized schedules production and level of automation have been presented in Tables 13. Regarding utility, the qualities which made the method more useful and applicable in industry, including different construction methods considering, resource types considering and applied sequencing rules have been summarized and presented in Table 1. The level of scheduling (e.g. activity level, project level and construction zone level) as well as the capability of proposed methods in generating optimized schedules has been showed in Table 2.

Table 1. Comparison of the utility of automated construction scheduling methods

\begin{tabular}{|c|c|c|c|}
\hline Methods & $\begin{array}{l}\text { Different construction } \\
\text { method considering }\end{array}$ & $\begin{array}{l}\text { Resource types } \\
\text { considering }\end{array}$ & Applied sequencing rules \\
\hline A & Yes (via templates) & $\begin{array}{l}\text { Labour, Material } \\
\text { and equipment }\end{array}$ & $\begin{array}{l}\text { Components and activity } \\
\text { precedence constraint }\end{array}$ \\
\hline B & Yes (via knowledge bases) & Labour & Stored If-then logic dependencies \\
\hline $\mathrm{C}$ & Yes (CBR based) & - & $\begin{array}{l}\text { task constraints from IFC model, } \\
\text { schedule from case database }\end{array}$ \\
\hline $\mathrm{D}$ & Yes (via templates) & $\begin{array}{l}\text { Labour, Material } \\
\text { and equipment }\end{array}$ & $\begin{array}{l}\text { Predefined Tasks and sequences } \\
\text { in Stroboscope simulation }\end{array}$ \\
\hline $\mathrm{E}$ & $\begin{array}{l}\text { Yes (for Panelised } \\
\text { construction) }\end{array}$ & $\begin{array}{l}\text { Resource } \\
\text { constraint }\end{array}$ & $\begin{array}{l}\text { Dynamic precedence constraints } \\
\text { between activities in simulation }\end{array}$ \\
\hline
\end{tabular}

Table 2. Comparison of level of scheduling and optimization capability

\begin{tabular}{ccc}
\hline Methods & Scheduling level & $\begin{array}{c}\text { optimized schedules production } \\
\text { capability }\end{array}$ \\
\hline A & $\begin{array}{c}\text { Different LoD due to hierarchical product, } \\
\text { process and construction method model } \\
\text { B }\end{array}$ & Project level \\
C & Case-dependent & No \\
D & Automatic: Project level & Case-dependent \\
& Manual: higher level schedules in MS project & No \\
E & Component-centric activity level & $\begin{array}{c}\text { PSO to optimize the activity } \\
\text { sequences with minimizing the } \\
\text { total project duration and solve } \\
\text { RCPSP problem }\end{array}$ \\
\hline
\end{tabular}


Furthermore, regarding the level of automation, the capability of the selected methods in automating the process of generating construction schedules has been investigated and categorized into four groups including preparation of required data, activity duration estimation, sequencing rules allocation and schedule generation as shown in Table 3.

Table 3. Investigation of the level of automation

\begin{tabular}{|c|c|c|c|c|}
\hline Methods & Preparation of required data & $\begin{array}{l}\text { Activity } \\
\text { duration } \\
\text { estimation }\end{array}$ & $\begin{array}{l}\text { Sequencing } \\
\text { rules } \\
\text { allocation }\end{array}$ & $\begin{array}{l}\text { Schedule } \\
\text { generation }\end{array}$ \\
\hline A & $\begin{array}{l}\text { Manual: CAD model, knowledge about } \\
\text { activity generation, sequencing and } \\
\text { resource requirements, Construction } \\
\text { method selection by user } \\
\text { Automatic: building product model }\end{array}$ & No & $\begin{array}{l}\text { Manually } \\
\text { selected }\end{array}$ & $\begin{array}{l}\text { Symbolic } \\
\text { activity } \\
\text { network in } \\
\text { Process } \\
\text { model }\end{array}$ \\
\hline B & $\begin{array}{l}\text { Manual: 2D CAD model, the third } \\
\text { dimension; zone data of project, } \\
\text { Knowledge base relating to CAD } \\
\text { drawing interpretation, activity } \\
\text { breakdown and logic dependencies }\end{array}$ & Yes & $\begin{array}{l}\text { Automatic } \\
\text { based on } \\
\text { logic } \\
\text { dependencies }\end{array}$ & $\begin{array}{l}\text { Automatic } \\
\text { Network } \\
\text { diagram } \\
\text { generation }\end{array}$ \\
\hline $\mathrm{C}$ & $\begin{array}{l}\text { Manual: case database, BIM model, } \\
\text { construction phase definition } \\
\text { Automatic: Constraint attributes of } \\
\text { building elements }\end{array}$ & $\begin{array}{c}\text { Yes (case- } \\
\text { based) }\end{array}$ & $\begin{array}{l}\text { Semi- }^{-} \\
\text {automatic } \\
\text { based on } \\
\text { existed cases }\end{array}$ & $\begin{array}{l}\text { Semi- } \\
\text { automatic } \\
\text { based on } \\
\text { cases }\end{array}$ \\
\hline $\mathrm{D}$ & $\begin{array}{l}\text { Manual: BIM model, triple task } \\
\text { productivity value, number of workers, } \\
\text { cranes and sets of forms, Stroboscope } \\
\text { activity network production } \\
\text { Automatic: calculated QTO } \\
\text { information through developed BIM } \\
\text { model/ single Stroboscope input file for } \\
\text { simulation }\end{array}$ & $\begin{array}{c}\text { Automatic } \\
\text { by .str } \\
\text { templates }\end{array}$ & $\begin{array}{c}\text { Automatic by } \\
\text { simulation } \\
\text { model }\end{array}$ & $\begin{array}{l}\text { Automatica } \\
\text { lly } \\
\text { produced } \\
\text { in MS } \\
\text { Excel and } \\
\text { Project file }\end{array}$ \\
\hline E & $\begin{array}{c}\text { Manual: BIM model, Work package } \\
\text { and resource availability items in MS } \\
\text { ACCESS tables, Partial activity } \\
\text { network building } \\
\text { Automatic: enriched information } \\
\text { entities as input for process simulation }\end{array}$ & $\begin{array}{l}\text { Automatic } \\
\text { by process } \\
\text { simulation } \\
\text { model }\end{array}$ & $\begin{array}{l}\text { Automatic by } \\
\text { process } \\
\text { simulation } \\
\text { model }\end{array}$ & $\begin{array}{l}\text { Automatica } \\
\text { lly } \\
\text { presented } \\
\text { in MS } \\
\text { Project file }\end{array}$ \\
\hline
\end{tabular}

\section{CONCLUSION}

Regarding the significance of planning phase in construction management, in order to reduce required time and to omit errors in construction scheduling, systems for automated generation of construction schedules have been developed. In this review paper, some existing methods have been classified in three main categories including AIbased, simulation-based and integrated BIM-based scheduling. Five specific methods have been selected and their strengths and weaknesses highlighted. As a result, the comparison revealed that the ability of BIM-based construction scheduling automation is 
significantly higher than of the other proposed methods. In fact, due to rich embedded building information in BIM models and its strong ability in information exchange, BIMbased integration methods have drawn attention of researchers to incorporate BIM models with other existing scheduling methods in order to provide powerful prototypes of automated construction scheduling.

One of the findings of this review was that there is still space for improvement in full utilization of extensive information and rules in BIM and in obtaining the required information in the desired level of construction scheduling. In fact, the main reason for the presented review was to establish a point of departure for an improved automated scheduling method, which shall be based on micro schedules (i.e. recipes), defined for each type of building elements in a BIM model, whereby the available resources, and the sequence restrictions shall be used as the main input. In this way, it is hoped to achieve better utilisation of the integrated information in a BIM model as well as enabling the evaluation of various scenarios for schedule optimisation.

\section{REFERENCES}

Aamodt, A. and Plaza, E. (1994). Case-based reasoning: Foundational issues, methodological variations, and system approaches. AI Communications, 7(1), pp.3959.

Akbas, R. (2004). Geometry-Based Modeling and Simulation of Construction Processes. PhD thesis. Civil and Environmental Engineering Dept., Stanford University

Ayman A.M. and Beliveau, Y.J. (1991). Knowledge-based planning system, Journal of Construction Engineering and Management, 117(1), pp.1-12.

Bjork, B.-C., (1994). RATAS PROJECT-DEVELOPING an Infrastructure for ComputerIntegrated construction, J. Comput. Civ. Eng, 8(4), pp.401-419.

Cherneff, J., Logcher, R. and Sriram, D., (1991). Integrating CAD with Construction Schedule Generation. Journal of Computing in Civil Engineering, 5(1), pp.64-84.

Currie, K.W. and Tate, A., (1991). O-Plan: The open planning Architecture. Artificial Intelligence, 52(1), pp.49-86.

Darwiche, A., Levitt, R. \& Hayes-Roth, B. (1989). OARPLAN:Generating project plans by reasoning about objects, actions and resources. AI EDAM, 2(3), pp.161-181.

Erol, K., Hendler, J. and Nau, D. (1994). "HTN Planning: Complexity and Expressivity." In Proceedings of the National Conference on Artificial Intelligence, John Wiley and Sons LTD, pp. 1123-1123.

Fischer, M.A. \& Aalami, F., (1996). Scheduling with Computer-Interpretable Construction method models Journal of Construction Engineering and Management Journal of Construction Engineering and Management Journal of Construction Engineering and Management, 122(4), pp.337-347.

Hendrickson, C., Zozaya-Gorostiza, C., Rehak, D., Baracco-Miller, E. \& Lim, P. (1986). An expert system for construction planning. J. Comput. Civ. Eng, 1(4), pp.253-269.

Kataoka, M., 2008. Automated Generation of Construction Plans from Primitive Geometries, Journal of Construction Engineering and Management, 134(8), pp.592600.

Kim, H., Anderson, K., Lee, S. \& Hildreth, J. (2013). Generating construction schedules through automatic data extraction using open BIM (building information modeling) technology. Automation in Construction, 35, pp.285-295. 
König, M., Koch, C., Habenicht, I. and Spieckermann, S. (2012). Intelligent BIM-based construction scheduling using discrete event simulation. Proceedings of the 2012 Winter Simulation Conference (WSC), pp.1-12.

Liu, H., Al-Hussein, M. and Lu, M., (2015). BIM-based integrated approach for detailed construction scheduling under resource constraints. Automation in Construction, 53, pp.29-43.

Lu, M. (2003). Simplified Discrete-Event Simulation Approach for Construction Simulation. J. of Const. Eng. and Manage., 129(5), pp.537-546.

Lu, M., Lam, H.-C. and Dai, F. (2008). Resource-constrained critical path analysis based on discrete event simulation and particle swarm optimization. Automation in Construction, 17(6), pp.670-681.

Martínez, J.C. (1996). STROBOSCOPE: State and Resource Based Simulation of Construction Processes. PhD thesis. University of Michigan. p.540.

McGartland, M.R., Hendrickson, C.T., (1986), Expert systems for construction project monitoring, J. of Constr. Eng. and Manage., 111(3), pp. 293-307.

Moon, H., Kim, H., Kamat, V., and Kang, L. (2014). BIM-Based Construction Scheduling Method Using Optimization Theory for Reducing Activity Overlaps. J. Comput. Civ. Eng., 10.1061/(ASCE) CP.1943-5487.0000342, 04014048.

Navinchandra, D., Sriram, D. and Logcher, R.D., (1988). GHOST: Project Network Generator. Manager, 2(3), pp.239-254. /(ASCE)0733-9399(1988)114:9(1542).

PMI. A Guide to the Project Management Body of Knowledge (PMBOK@ Guide). (2008). 5th edition. Project Management Institute, Pennsylvania, USA.

Rolston, D.W. (1988). Principles of artificial intelligence and expert systems development, New York N.Y.: McGraw-Hill.

Tauscher, E., Mikulakova, E., Beucke, K. and König, M. (2009). Automated Generation of Construction Schedules Based on the IFC Object Model. Computing in Civil Engineering (2009), 346(2009), pp.666-675.

Tauscher, E., Mikulakova, E., König, M. and Beucke, K., (2007). Generating Construction Schedules with Case-Based Reasoning Support, Computing in Civil Engineering (2007), pp.119-126.

Wang, H. and Song, X. (2015). Research on BIM Construction Schedule Generating Algorithm. International Journal of Simulation Systems, Science and Technology, 16(1B), p.10.1-10.7.

Wang, S.Q. (2001). ESSCAD: Expert System Integrating Construction Scheduling With Cad Drawing. Proceedings of the CIB W78 International Conference on IT in Construction in Africa, pp.1-14.

Wang, W.C., Weng, S.W., Weng, S.H. and Chen, C.Y. (2014), Integrating building information models with construction process simulations for project scheduling support, Automation in Construction, 37, pp.68-80.

Wu, I.C., Borrmann, A., Beißert, U., König, M. and Rank, E. (2010), Bridge construction schedule generation with pattern-based construction methods and constraint-based simulation, Advanced Engineering Informatics, 24(4), pp.379-388.

Xu, K., and Muñoz-Avila, H. 2008. "CaBMA: A Case-Based Reasoning System for Capturing, Refining, and Reusing Project Plans, Knowl Inf Syst, 15 (2): 215-232.

Mohamed, Y., S.A., 2000. Simphony: an integrated environment for construction simulation, Proceedings. In Winter Simulation Conference. Orlando, FL, USA, pp. 1907-1914.

Zhang, H., Tam, C.M. and Shi, J.J., 2002. Simulation-based methodology for project scheduling. Construction Management and Economics, 20(8), pp.667-678. 